\title{
The Role of the Leucocytosis Parameter in the Occurrence of Pregnancy Complications in Women with Periodontal Disease
}

\author{
CAMELIA FIERA MAGLAVICEANU ${ }^{1}$, EDWIN SEVER BECHIR ${ }^{2 *}$, MIHAELA JANA TUCULINA ${ }^{1}$, CONSTANTIN DAGUCI ${ }^{1}$, \\ IONELA TEODORA DASCALU ${ }^{1}$, LUMINITA DAGUCI ${ }^{1}$, ANDREEA NICOLA ${ }^{1}$, MIHAELA SANDA POPESCU ${ }^{1}$, MARILENA BATAIOSU ${ }^{1}$ \\ ${ }^{1}$ Medicine and Pharmacy University of Craiova, Faculty of Dental Medicine, 2-4 Petru Rares Str., 200349, Craiova, Romania \\ 2 Medicine, Pharmacy, Science and Technology University of Tirgu Mures, Faculty of Dental Medicine, 38 Gheorghe Marinescu Str., \\ 540142, Tirgu Mures, Romania
}

\begin{abstract}
For the present study, a total number of 109 pregnant patients in the second trimester of pregnancy were selected from the case studies of the Clinic of Obstetrics and Gynaecology of the Municipal Clinical Hospital Filantropia in Craiova. Among these, 56 patients had gingivitis, 26 had mild, moderate, or severe periodontitis, and 27 patients were used as a control segment. Each patient had her leukocytes values tested and they had their oral cavity examined. Leukocyte neutrophils are the primary cells of the body's defence system as well as primary protective cells against periodontal disease. Based on the study, we can say that there is a significant difference between the average number of leukocytes found in the four groups, because the result of the ANOVA test was below the threshold $p<0.001$. By analyzing the involvement of the leucocytosis parameter in the occurrence or presence of pregnancy complications, we found it present in periodontal disease pregnant women who had complications, namely: premature birth, preeclampsia, or intrauterine growth restriction.
\end{abstract}

Keywords: periodontitis, leukocytes, pregnant, preterm birth

Pregnancy is characterized by a profound change in the physiological functions of the pregnant woman's body. During pregnancy, there is a considerable increase in the metabolic needs as well as changes in the hormonal balance. These phenomena provide sufficient justification for haematological disorders. During normal pregnancy, changes occur and can be seen in haematological indices such as the number of red blood cells (haemoglobin), haemoglobin (HB) concentration, physiological anaemia, platelet count (PLT) and white blood cell count (WBC) .

The periodontal disease is a multifactorial pathological disease initiated by a gram negative bacterial infection (Actinobacillus Actinomycetemcomitans, Porphyromonas gingivalis, Bacteroides forsythus, Porphyromonas gingivalis, Prevotella intermedia) that contribute to the generation of a local immune response, and the presence of single microorganisms is not the only factor responsible for periodontal destruction [1-3]. However, Porphyromonas gingivalis has been commonly associated with various systemic diseases [4]. This is probably due to the fact that this bacterium has the ability to disseminate in the peripheral circulation and to cause inflammation in various areas of the body [5]. Leukocyte neutrophils are the primary cells of the body's defence system and primary protective cells against periodontal disease. The release of infiltrating leukocyte components, such as lysosomal enzymes and reactive oxygen species, which are normally intended to degrade ingested microbes, can also lead to tissue destruction and increased inflammatory response. The change in white blood cells number may become a valuable test for identifying asymptomatic women who may be at risk of premature birth [5].

Numerous studies have shown that women with periodontitis have two to three times more chances than healthy women to give birth prematurely or to have a baby with low weight at birth [6]. The mechanism responsible for the association between periodontal disease and complications of pregnancy seems to be the peripheral circulation of the placenta $[7,8]$.
The purpose of the study was to analyse the variation in the number of leukocytes in periodontal disease in the pregnant woman. It is quite difficult to determine the cause of leucocytosis in pregnancy because a mild leucocytosis, considered as a physiological condition, occurs, but infections such as those involved in the occurrence of periodontal disease can be considered as a major cause of leucocytosis.

\section{Experimental part \\ Material and method}

For the present study, a total number of 109 pregnant patients in the second trimester of pregnancy were selected from the case studies of the Clinic of Obstetrics and Gynaecology of the Municipal Clinical Hospital Filantropia in Craiova. The patients participating in the study were divided into three groups as follows:

1. a group of 56 pregnant patients with gingivitis

2. a group of 26 pregnant patients with periodontitis, out of which:

- 16 cases with mild chronic marginal periodontitis = mild PMC

- 8 cases with medium chronic marginal periodontitis $=$ medium $\mathrm{PMC}$

- 2 cases with chronic severe marginal periodontitis = severe PMC

3. a group of 27 healthy pregnant patients as a control group

Each patient had their leukocyte value tested and they were examined from the periodontal point of view. The data obtained were recorded in a personal record of pregnant periodontal control adapted to the model proposed by Dumitriu [9]. For all the patients under study, the time of birth was observed, whether or not there had been premature births before.

The study was conducted in full compliance with the ethical principles contained in the Declaration of Human Rights adopted in Helsinki, which are in line with the Good Practice Guidelines for Clinical Studies and with the legal 
regulations in force. The informed consent for the use of the data for this study was obtained from the patients included in this study. The study was approved by the Ethics Committee of the University of Medicine and Pharmacy Craiova.

In the beginning of the study, we felt there were no foreseeable risks for patients, and the benefits were obvious. For a better accuracy of the study, we considered a number of inclusion criteria and exclusion criteria, the study being better targeted and centred on a particular representative group.

Criteria for being included in the study:

- Age $>18$ years old.

- Second trimester of pregnancy starting at 22 weeks.

- Diagnosis of periodontal disease after a dental examination.

- At least 20 teeth present in the arch.

- No moderate or severe dental caries.

- Single pregnancy

- No systemic diseases.

- Without severe cardiovascular disease, diabetes, hyperthyroidism, and / or other systemic diseases.

- No immunodeficiency diseases.

- Available to be observed during the study.

Criteria for being excluded from the study:

-Age $<18$ years old

-Less than 20 teeth.

-Multiple pregnancy

-Dental examination contraindications and treatment, such as cardiac disorders.

-Undergoing a periodontal treatment over the last six months.

-Antibiotic therapy during the last month

-With a disease mentioned in the inclusion criteria.

The biochemical evaluation and investigations were performed in the haematology laboratory at the Municipal Clinical Hospital in Craiova. The statistical analysis of the collected data was carried out within the Biostatistics discipline of the University of Medicine and Pharmacy in Craiova. Microsoft Excel (Microsoft Corp., Redmond, WA, USA), together with the XLSTAT suite for MS Excel (Addinsoft SARL, Paris, France) and IBM SPSS Statistics 20.0 (IBM Corporation, Armonk, NY), DOOR). The measured parameters for the subjects included in this study were stored in Excel files. The secondary processing of the data, the calculation of the basic statistical parameters, the average and the standard deviation, their ratio - the coefficient of variation and their graphical representation were performed with Excel using the Pivot Tables, Functions-Statistical, Chart and Data Analysis ANOVA test.

\section{Results and discussions}

Starting from the premise that leucocytosis, mainly due to neutrophilia, is the most important change in the body's defence system during pregnancy, we wanted to see how the leukocyte count changes in pregnant women. We chose $11,000 / \mu \mathrm{L}$ as cut-off for the number of leukocytes in pregnancy. Determination of the number of leukocytes in the studied subgroups showed that for the control group we had an average value of 10,240 leukocytes / $\mu \mathrm{L} \pm 0.71$ standard deviation. For gestational pregnancies, the medium leukocyte number was 13,150 leucocytes / $\mu \mathrm{L} \pm$ 2.55 standard deviation.

In mild PMC pregnant women, the medium leukocyte number was 13,940 leukocytes / $\mu \mathrm{L} \pm 2.28$ standard deviation, and in medium and severe PMC pregnantwomen the medium leukocyte number was 14.110 leukocytes / $\mu \mathrm{L} \pm 2.64$ standard deviation.

Following the study, we can say that there is a significant difference between the average number of leukocytes found in the four groups, as the ANOVA test result was below the $p<0.001$ threshold. Continuing the statistical analysis to identify the pairs between which the differences are manifested we showed that the control group has differently high values significantly different from all other lots but also that the gingivitis group has significantly lower values than both PMC lots. There is no significant difference between patients with mild PMC and medium-to-severe PMC.

Analysing the implication of this parameter, leucocytosis, in the occurrence or presence of pregnancy complications, we found that leucocytosis is present in pregnant women with periodontal disease who have experienced complications: premature birth, preeclampsia or intrauterine growth restriction ( Table 1).

The result of the square Chi test is statistically significant, $p<0.05$, so there is a possibility that the identification of a high leukocyte number is useful in detecting premature birth (Table 2).

Both the OR (Odds ratio) value and the RR (Risk ratio) value are statistically significant (the neutral result, 1 is not included in the $95 \%$ confidence interval for either of the two statistical indicators), so we can state that there is a link between an increased value of leukocytes and the possibility of premature birth (Table 3).

\begin{tabular}{|c|c|c|c|c|c|c|}
\hline & Premature B & Premature B & Term birth & Term birth & Total & Total \\
\hline Le $>11000$ & 30 & $46.88 \%$ & 34 & $53.13 \%$ & 64 & $100.00 \%$ \\
\hline$L e<11000$ & 6 & $13.33 \%$ & 39 & $86.67 \%$ & 45 & $100.00 \%$ \\
\hline Total & 36 & $33.03 \%$ & 73 & $66.97 \%$ & 109 & $100.00 \%$ \\
\hline$p$ Chi square & $\mathbf{0 . 0 0 0 2 5}$ & HS & & & & \\
\hline
\end{tabular}

Table 1

STATISTICAL ANALYSIS OF LEUCOCYTOSIS IN PREMATURE BIRTH
Table 2

OR AND RR VALUE FOR LEUKOCYTOSIS IN PREMATURE BIRTH

\begin{tabular}{|l|l|l|}
\hline OR & $\mathbf{5 . 7 3 5}$ & \\
\hline I.confidence 95\% & 2.131 & 15.433 \\
\hline $\mathbf{R R}$ & 3.516 & \\
\hline I.confidence 95\% & 1.307 & 9.460 \\
\hline
\end{tabular}

Table 3

STATISTICAL PARAMETERS FOR LEUKOCYTOSIS IN PREMATURE BIRTH

\begin{tabular}{|l|c|}
\hline Statistical parameter & $\%$ \\
\hline Accuracy & $63.30 \%$ \\
\hline Sensitivity & $83.33 \%$ \\
\hline Specificity & $53.42 \%$ \\
\hline Positive predictive value & $46.88 \%$ \\
\hline Negative predictive value & $86.67 \%$ \\
\hline
\end{tabular}




\begin{tabular}{|c|c|c|c|c|c|c|}
\hline & Preeclampsy & Preeclampsy & Without PE & Without PE & Total & Total \\
\hline Le $>11000$ & 18 & $28.13 \%$ & 46 & $71.88 \%$ & 64 & $100.00 \%$ \\
\hline Le $<11000$ & 2 & $4.44 \%$ & 43 & $95.56 \%$ & 45 & $100.00 \%$ \\
\hline Total & 20 & $18.35 \%$ & 89 & $81.65 \%$ & 109 & $100.00 \%$ \\
\hline$p$ Chi square & $\mathbf{0 . 0 0 1 6 6}$ & $\mathrm{S}$ & & & & \\
\hline
\end{tabular}

Table 4

STATISTICAL ANALYSIS OF LEUKOCYTOSIS IN PREECLAMPSIA
Table 5

OR AND RR VALUE FOR LEUCOCYTOSIS IN PREECLAMPSIA

\begin{tabular}{|l|l|l|}
\hline OR & 8.413 & \\
\hline I.confidence 95\% & 1.842 & 38.424 \\
\hline RR & 6.328 & \\
\hdashline I.confidence 95\% & 1.386 & 28.902 \\
\hline
\end{tabular}

Table 6

STATISTICAL PARAMETERS FOR LEUCOCYTOSIS IN PREECLAMPSIA

\begin{tabular}{|l|c|}
\hline Statistical parameter & $\%$ \\
\hline Accuracy & $55.96 \%$ \\
\hline Sensitivity & $90.00 \%$ \\
\hline Specificity & $48.31 \%$ \\
\hline Positive predictive value & $28.13 \%$ \\
\hline Negative predictive value & $95.56 \%$ \\
\hline
\end{tabular}

\begin{tabular}{|c|c|c|c|c|c|c|c|}
\hline & RCIU & RCIU & Without RCIU & Without RCIU & Total & Total & \\
\hline$L e>11000$ & 14 & $21.88 \%$ & 50 & $78.13 \%$ & 64 & $100.00 \%$ & $\begin{array}{l}\text { lable I } \\
\text { STATISTICAI ANAIYSIS }\end{array}$ \\
\hline$L e<11000$ & 3 & $6.67 \%$ & 42 & $93.33 \%$ & 45 & $100.00 \%$ & OF LEUKOCYTOSIS IN \\
\hline Total & 17 & $15.60 \%$ & 92 & $84.40 \%$ & 109 & $100.00 \%$ & $\mathrm{RCIU}$ \\
\hline p Chi square & 0.03119 & $\mathrm{~S}$ & & & & & \\
\hline
\end{tabular}

Table 8

OR AND RR VALUE FOR LEUCOCYTOSIS IN RCIU

\begin{tabular}{|c|c|c|}
\hline OR & 3.920 & \\
\hline I.confidence 95\% & 1.055 & 14.568 \\
\hline RR & 3.281 & \\
\hline I.confidence 95\% & 0.883 & 12.194 \\
\hline
\end{tabular}

The number of leukocytes over 11,000 could be used as an indicator of premature birth as it has an accuracy of $63.3 \%$ and a sensitivity of $83.33 \%$, but with certain reservations, because the specificity is $53.42 \%$, under the recommended threshold of $75 \%$. The positive predictive value shows that if we have over 11,000 leukocytes, the probability of having a premature birth is only $46.88 \%$, and the negative predictive value shows that if we have leukocytes $<11,000$, the probability of having a premature birth is only $13.33 \%$.

The number of leukocytes is increased in cases with preeclampsia, the link between these two parameters being statistically studied ( Table 4).

The result of the square Chi test is statistically significant $(p<0.05)$, so there is a possibility that the identification of an elevated leukocyte number is useful in the detection of preeclampsia (Table 5).

Both the OR value and the RR value are statistically significant (the neutral result, 1 is not included in the $95 \%$ confidence interval for either of the two statistical indicators), so we can state that there is a link between an increased value of leukocytes and the possibility of preeclampsia (Table 6).

The sensitivity of $90 \%$ makes us believe that the leukocyte number $>11,000$ could be useful in estimating a future preeclampsia state if it were used together with another test with a specificity above the 75\% threshold.

Only the negative predictive value has practical applicability, $93.33 \%$ of patients with less than 11,000 leukocytes / $\mu \mathrm{L}$ having pregnancy without preeclampsia.

In the case of intrauterine growth restriction (RCIU), the leukocyte number involvement has also been studied to see if this parameter is involved in the production or can detect the presence of an RCIU (Table 7 ).
The result of the Chi square test is statistically significant $(p<0.05)$, so there is a possibility that the identification of an elevated leukocyte number is useful in detecting RCIU (Table 8).

The fact that the limit of the confidence interval for OR is very close to 1 and that of RR is below 1 leads us to consider that there is a poor, almost unsupported, relationship between an increased leukocyte value and the possibility of occurrence of RCIU (Table 9).

\section{Table 9}

STATISTICAL PARAMETERS FOR LEUKOCYTOSIS IN RCIU

\begin{tabular}{|l|c|}
\hline \multicolumn{1}{|c|}{ Statistical perameter } & $\%$ \\
\hline Accuracy & $51.38 \%$ \\
\hline Sensitivity & $82.35 \%$ \\
\hline Specificity & $45.65 \%$ \\
\hline Positive predictive value & $21.88 \%$ \\
\hline Negative predictive value & $93.33 \%$ \\
\hline
\end{tabular}

Only the negative predictive value has practical applicability, $93.33 \%$ of patients with less than 11,000 leukocytes / ìL having non-RCIU pregnancies. The rest of the statistical parameters, accuracy, sensitivity, specificity, positive predictive value do not have practical applicability.

In recent years the association between periodontitis and pregnancy complications has been extensively investigated, and the results are controversial. Noack et al. found that periodontitis is not a detectable risk factor for intrauterine growth restriction [10]. Mitchell-Lewis et al. found no correlation between periodontal disease and premature birth [11]. According to Conde-Agudelo et al. [12], urinary tract infection during pregnancy and periodontal disease is significantly related to the development of preeclampsia.

Whether periodontitis is causally associated with pregnancy complications or it is just a marker for other risk factors, it is a problem that continues to be debated. Periodontitis and pregnancy complications may be associated with a systemic chronic inflammatory status for both the mother and the foetus in response to pathogens present in the mother's oral cavity. Alternatively, these pathogens can affect the uterus directly through recurrent bacteraemia with microbial species associated with 
periodontitis [13]. Due to the association between infection or inflammation and premature birth, preeclampsia and intrauterine growth restriction, [14] the researchers attempted to identify inflammatory biomarkers that may predict these complications [15]. Leucocytosis, mainlydue to neutrophilia, the most important change in the body's defence system during pregnancy [16]. Granulocytes, especially neutrophils, are the first line of defence against infections [17]. Their value increases slowly and gradually from the first trimester of pregnancy to the third quarter. Expert studies have shown that the number of neutrophils in the peripheral blood of pregnant women increases in the case of premature birth [18].

The number of leukocytes is increased in cases with preeclampsia, the link between these two parameters being studied statistically. The results of our study are consistent with the results of the study conducted by Canzoneri et al. which showed that leukocyte number increases significantly in severe cases of preeclampsia [19]. Lurie etal. observed that the severity of preeclampsia is associated with significant increases in neutrophil number [20]. A possible explanation for this phenomenon is that in case of degranulation of neutrophils when they invade tissues, myeloperoxidases are released and hydrogen peroxide accumulates. By combining it with chlorine, hypochlorous acid results in a state of toxicity in the body, facilitating preeclampsia [21,22].

Metabolic syndrome and diabetes were quoted as the determiners of premature birth $[23,24]$. This was one reason why we did notstudy pregnant women with dysmetabolic disease or diabetes.

During pregnancy, low $\mathrm{Hb}$ levels, which indicate moderate (70 to $90 \mathrm{~g} / \mathrm{l}$ ) or severe (less than $70 \mathrm{~g} / \mathrm{l}$ ) anaemia, are associated with increased maternal and infant mortality and infectious disease [25]. This finding makes us extend our study about the changes in haemoglobin in pregnant women.

\section{Conclusions}

Our study has shown that there is some correlation between maternal periodontal health, preeclampsia and premature birth or intrauterine growth restriction. Increasing the number of leukocytes associated with the installation of a marginal periodontitis in pregnant women could be a valuable diagnostic test in preventing premature birth. Increasing number of neutrophils in pregnancy can be considered as a determining factor in preeclampsia.

The results of this study reinforce the idea that pregnancy is a phenomenon that induces a physiological change in certain parameters of the blood, but the occurrence of pathogenic infectious factors such as those involved in periodontal disease requires greater attention in optimal maternal and foetal care. Therefore, familiarizing clinicians with these physiological and pathological changes related to pregnancy will encourage optimal management of pregnancies, preventing complications.

\section{References}

1.VIDITA GURBAN, C, SUCIU, O, VLAIA, L, GOTIA, LS, CORNIANU, M, ZAMBORI, C, MOTOC, M, VLAIA, V, VELEA, I, PRICOP, M, Rev. Chim. (Bucharest), 2016, 67, no.10, p. 1952-1956.

2.TAKEDA, J, FANG, $X$, OLSON, DM, BMC Pregnancy and Childbirth, 2017, 17(16), p. 1-7, doi 10.1186/s12884-016-1204-5.

3.ODOR, A.A., BECHIR, E.S., VIOLANT, D., BADEA, V., Rev. Chim. (Bucharest), 69, no.8, 2018, p. 2081

4.LEE, CC, AVALOS, AM, PLOEGH, HL, Nat Rev Immunol, 2012, 12(3), p. 168.

5.KATZ, J, CHEGINI, N, SHIVERICK, KT, LAMONT, RJ , J Dent Res, 2009, 88(6), p. 575.

6.SADDKI, N, BACHOK, N, HUSSAIN, NH, ZAINUDIN, SL, SOSROSENO, W. Community Dent Oral Epidemiol., 2008, 36, p. 296

7.KINGMAN, A., ALBANDAR, J M., Periodontal 2000, 2002, 29, p. 11.

8.SWATI, P, THOMAS, B, VAHAB, SA, KAPAETTU, S, KUSHTAGI, P, Arch Gynecol Obstet., 2012, 285(3), p. 613.

9.DUMITRIU, HT, Parodontologie, Ed.Viaa Medicalã Româneascã, Bucuresti, 2009

10.NOACK B, KLINGENBERG J, WEIGELT J , HOFFMANN T.J Periodontal Res., 2005, 40(4) p. 3394.

11.MITCHELL-LEWIS, D, ENGEBRETSON, SP, CHEN, J, LAMSTER, IB, PAPAPANOU, PN.. Eur J Oral Sci,, 2001, 109(1), p. 34.

12.CONDE-AGUDELO, A, VILLAR, J, LINDHEIMER, M, Am J Obstet Gynecol, 2008, 9(2), p. 46.

13. RADULESCU, A, MADAN, V, AUNGURENCI, A, BRATU, O, FARCAS, C, DINU, M, MISCHIANU, D. Romanian J ournal of Military Medicine, 2015, 118, no. 3, p. 20.

14.GIBBS, RS, Ann Periodontol, 2001, 6(1), p. 153

15.GOLDENBERG, RL, CULHANE, JF, IAMS, JD, ROMERO, R, Lancet, 2008, 371(9606), p. 75.

16.CHANDRA, S, TRIPATHI, AK, MISHRA, S, AMZARUL, M, KUMAR VAISH, A, Indian Journal of Hematology and Blood Transfusion, 2012, no 28(3), p. 144.

17.SADIK, CD, KIM, ND, LUSTER, AD. Trends Immunol., 2011, 32, p. 452.

18.JIANHONG, Z, SHYNLOVA, O, SABRA, S, BANG, A, BRIOLLAIS, L, STEPHEN, J, J. Cell. Mol. Med., 2017, Vol 21, No 10, p. 2386.

19.CANZONERI, BJ, DAVID, F, LEWIS, GROOME, L, WANG, YMD, Am J Perinatol., 2009, 26 (10), p. 729.

20.LURIE, S, FRENKEL, E, TUVBIN, Y. Gynecol Obstet Invest., 1998, 45, p. 229

21.KLEBANOFF S) . MYELOPEROXIDASE: friend and foe. J Leukoc Biol., 2005, 77(5), p. 598.

22.SHAH TJ, WALSH SW. Am J Obstet Gynecol., 2007, 196(1), p. 48.e148.e8.

23.CHATZI L, et al. Diabetes Metab., 2009, 35, p. 490. doi: 10.1016/ j.diabet.2009.07.003.

24.HERRERA E, ORTEGA-SENOVILLA H. BestPract Res Clin Endocrinol Metab., no 24, 2010, p. 515. doi: 10.1016/j.beem.2010.05.006.

25. CHRISTIAN, P, JIANG, T, KHATRY, SK, LECLERQ, SC, SHRESTHA, SR, WEST, KP. American J ournal of Clinical Nutrition, 2006, 83, p. 788.

Manuscript received: 10.07 .2018 